\title{
GCU
}

Glasgow Caledonian

University

University for the Common Good

\section{Assessment of porcine endogenous retrovirus transmission across an alginate barrier used for the encapsulation of porcine islets}

Crossan, Claire; Mourad, Nizar I.; Smith, Karen; Gianello, Pierre ; Scobie, Linda

Published in:

Xenotransplantation

DOI:

10.1111/xen.12409

Publication date:

2018

Document Version

Author accepted manuscript

Link to publication in ResearchOnline

Citation for published version (Harvard):

Crossan, C, Mourad, NI, Smith, K, Gianello, P \& Scobie, L 2018, 'Assessment of porcine endogenous retrovirus transmission across an alginate barrier used for the encapsulation of porcine islets', Xenotransplantation, vol. 25, no. 6, e12409. https://doi.org/10.1111/xen.12409

\section{General rights}

Copyright and moral rights for the publications made accessible in the public portal are retained by the authors and/or other copyright owners and it is a condition of accessing publications that users recognise and abide by the legal requirements associated with these rights.

Take down policy

If you believe that this document breaches copyright please view our takedown policy at https://edshare.gcu.ac.uk/id/eprint/5179 for details of how to contact us. 


\section{Assessment of PERV transmission across an alginate barrier used for the encapsulation of porcine islets.}

\section{Abstract}

Subcutaneous implantation of a macroencapsulated patch containing human allogenic islets has been successfully used to alleviate type 1 diabetes mellitus (T1DM) in a human recipient without the need for immunosuppression. The use of encapsulated porcine islets to treat T1DM has also been reported. Although no evidence of pathogen transfer using this technology has been reported to date, we deemed it appropriate to determine if the encapsulation technology would prevent the release of virus, in particular, the porcine endogenous retrovirus (PERV). To do this, we cultured HEK293 (human epithelial kidney) and ST (swine testis) cells with macro-encapsulated pig islets embedded in an alginate patch, macro encapsulated PK15 (swine kidney epithelial) cells embedded in an alginate patch and free PK15 cells. Cells and supernatant were harvested at weekly time points from the cultures for up to 60 days and screened for evidence of PERV release using qRT-PCR to detect PERV RNA and SG-PERT to detect reverse transcriptase. No PERV virus, or evidence of PERV replication, was detected in the culture medium of HEK293 or pig cells cultured with encapsulated porcine islets. Increased PERV activity relative to the background was not detected in ST cells cultured with encapsulated PK15 cells. However, PERV was detected in 1 of the 3 experimental replicates of HEK293 cells cultured with encapsulated PK15 cells. Both HEK293 and ST cells cultured with free PK15 cells showed an increase in reverse transcriptase (RT) detection. Thus, with the exception of one replicate, there does not appear to be evidence of transmission of replication competent PERV from the encapsulated islet cells or the positive control PK15 cells across the alginate barrier. The detection of PERV in one experimental replicate using encapsulated PK15 cells would suggest the alginate barrier of this replicate may have become compromised, emphasizing the importance of quality control when producing encapsulated islet patches. 


\section{Introduction:}

Alginate encapsulation of porcine islet cells proposes to permit the implantation of porcine islets as a treatment for type 1 diabetes mellitus (T1DM) in humans, whilst negating the need for immune suppression and reducing the risk of zoonosis. Microencapsulation i.e. entrapment of individual islets or small groups of islets within spherical capsules (150-1500 $\mu \mathrm{m}$ ) offers better oxygenation and overall diffusion for islet cells while macroencapsulation i.e. holding the islets in a single major device (also referred to as a patch) offers the advantage of easy retrieval and even fresh cell replenishment if necessary. Alginate is probably the most studied biomaterial for islet encapsulation due to its biocompatibility, selective permeability and the possibility to use it in both micro- and macroencapsulation techniques. In 2011, Basta et al. were the first to report successful microencapsulated islet allotransplantation in 4 non immunosuppressed diabetic patients with improvement of glycemia and $\mathrm{HbA}_{1 c}$ as well as reduced exogenous insulin requirements over a follow-up period of 3 years ${ }^{1}$. Human clinical trials of microencapsulated porcine islets conducted in New Zealand (NZ) and Argentina have also reported no evidence of pathogen transmission but limited efficacy, with patients exhibiting a $\geq 50 \%$ reduction in hypoglycemic episodes after 1 year when compared with control groups ${ }^{2,3}$.

The alginate-encapsulated monolayer device is composed of decellularized allogeneic (human fascia lata) or xenogeneic (porcine acellular dermis) collagen on which porcine islets are seeded. The ensemble is then embedded in alginate to constitute a patch of macroencapsulated islets. Non-human primate studies have demonstrated this approach as successful in correcting chemically induced diabetes for up to 6 months ${ }^{4}$. Despite the in vivo success of T1DM correction using encapsulated porcine islets, some concerns still remain in regards to safety, in particular the possible transmission of porcine endogenous retrovirus (PERV). Data from the NZ trial ${ }^{2}$ and Argentinian trial ${ }^{5}$ have demonstrated an absence of PERV in recipients of porcine encapsulated islets. However, it is worth noting that in both instances the human and primate recipients were immunocompetent. Thus, it is difficult to determine if the absence of PERV is due to the impermeability of the alginate to the virus or the efficiency of the immune system in targeting PERV escaping the patch. Given the lack of studies examining permeability of alginate patches to viruses, for this study, we deemed it 
appropriate to determine if the encapsulation technology would prevent the release of PERV using an in-vitro co-culture model. 


\section{Materials and Methods:}

Isolation and preparation of islets

Pancreatic islets were isolated from adult Landrace (2-3 year old) pigs (RA-SE genetics, Belgium) and cultured in vitro for 24-72 hours as previously described ${ }^{6}$ before undergoing encapsulation. 5000 islet equivalents (IEQ) or 25000 cells (PK15) were seeded on a collagen matrix (acellular porcine dermis), covered with a $300 \mu \mathrm{m}$ mesh, stabilized with surgical clips and coated with $3 \%$ sterile lyophilized high mannuronic acid content (SLM) alginate solution with a permeability up to $150 \mathrm{kDa}$ (Novamatrix, Norway) ${ }^{7}$. The patch was immersed in MOPS (3-(N-morpholino)propanesulfonic acid) buffer $+100 \mu \mathrm{M} \mathrm{CaCl}$ for 7 minutes to allow alginate polymerization, then washed in MOPS for 5 minutes and transferred to CMRL culture medium (Mediatech, USA) supplemented with $10 \%$ heat-inactivated fetal bovine serum (FBS), 1\% penicillin and $1 \%$ streptomycin (stock concentration 10,000U/ml; all from Westburg, Netherlands).

Co-culture for PERV transmission

HEK293 (ATCC ${ }^{\circledR}$ CRL-1573) or ST (ATCC ${ }^{\circledR}$ CRL-1746) cells $\left(5 \times 10^{4} /\right.$ well) were seeded in the lower compartment of Transwell 6-well plates (Corning, USA) with $2 \mathrm{ml}$ of dulbecco's modified eagle medium (DMEM) supplemented with $10 \%$ heat-inactivated fetal bovine serum (FBS), 1\% penicillin and 1\% streptomycin (stock concentration 10,000U/ml; all from Westburg, Netherlands). Patches containing islets or PK15 (ATCC ${ }^{\circledR}$ CCL-33) cells were placed in the insert (upper compartment) with $2 \mathrm{ml}$ of DMEM. For positive controls the upper compartment was seeded with $2.5 \times 10^{4}$ PK15 cells without encapsulation. Supernatants, passed through a $0.45 \mu \mathrm{m}$ Acrodisc syringe filter (VWR, Belgium), were collected weekly (in triplicate) from the lower compartment for an 8 week period to check for viral transmission by detection of RT, viral RNA and intact virus. The target cells were passaged over the study period and refreshed using 50\% conditioned media. ST cells were split at a ratio of 1:6, HEK293 and PK15 cells were split at a ratio of 1:35. PK15 cells used were checked for RT release to indicate active PERV replication by SG-PERT, prior to utilization and maintained in a separate plate throughout the study. 


\section{PERV screening}

The presence of PERV RNA and reverse transcriptase (RT) were used as indicators of PERV release from donor cells (encapsulated or free), into the cell medium shared with target cells. Supernatant samples were assayed for the presence of PERV RNA using a TaqMan based qRT-PCR targeting the pol region using QuantiTect ${ }^{\circledR}$ virus reagents (Qiagen, Crawley, UK) and Viia7 real time cycler (Thermo Fisher, Paisley, UK), primers and cycling conditions are previously described ${ }^{7}$. SG-PERT was used to detect reverse transcriptase (RT), using murine leukemia virus RT as a standard and a method previously described ${ }^{8}$. Capsid integrity testing was carried out to distinguish between intact virions and cell derived naked RNA or reverse transcriptase. This involved ultracentrifugation of samples at $200,000 \times \mathrm{xg}$ for $70 \mathrm{mins}$ at $4^{\circ} \mathrm{C}$, followed by RNase treatment of re-suspended sediment (RNase A (Qiagen Crawley, UK) $[5 \mathrm{U} / \mathrm{ml}]$ and RNase T1 (Thermo Fisher, Paisley, UK) $[50 \mathrm{U} / \mathrm{ml}]$ ) at $37^{\circ} \mathrm{C}$ for 1 hour, RNase inactivation with $10 \mathrm{mM}$ DTT (Sigma-Aldrich, Gillingham, UK) at $37^{\circ} \mathrm{C}$ for 1 hour, viral RNA isolation and qRT-PCR. Western blot analysis was also carried out on HEK293 supernatants; $15 \mu \mathrm{l}$ of culture medium was electrophoresed using 8-16\% Novex ${ }^{\mathrm{TM}}$ gels (Life Technologies, Paisley, UK), transferred to a nitrocellulose membrane and probed with a Rabbit anti-gag antibody [1:1000] (kindly provided by Prof Yasu Takeuchi, UCL). Provirus analysis of target cells was carried out on DNA isolated from cells using the DNeasy mini kit (Qiagen, Crawley, UK) and TaqMan qPCR with QuantiTect virus reagents ${ }^{\circledR}$ and a Viia7 real time cycler (Thermo Fisher, Paisley, UK), as described previously ${ }^{7}$. Statistical analysis was carried out using an unpaired student's t-test. 


\section{Results}

As described in the methods, supernatant samples were collected on a weekly basis from each experiment 1-9 in triplicate (Table 1) and assayed for PERV RNA and RT (Figures 1 and 2). A significant increase in RT was detected by SG-PERT analysis in ST cell culture media exposed to free PK15 cells (Experiment 6), in comparison to ST cell only controls (Experiment 8) over time (week $4 p=0.0284$, week $6 p<0.0001$, week $8 p<0.0001$ ) (Figure 1a). However, ST cells exposed to encapsulated islet and PK15 cells did not show RT levels higher than the ST negative control cells at any time point over the 8 week period (Figure $1 \mathrm{~A})$.

Analysis of HEK293 culture media shows high RT levels (48266 SD $\pm 13370 \mu \mathrm{URT} / \mathrm{ml}$; range $(40,708-63,704 \mu \mathrm{URT} / \mathrm{ml})$ in cell culture supernatant from HEK293 cells exposed to free PK15 cells at weeks 4,6 and 8 (Figure 1B), but no RT activity was observed in supernatant samples from HEK293 cells exposed to encapsulated islets or control HEK293 cells (Figure 1B). However, low level (1123 $\pm 1040 \mu \mathrm{URT} / \mathrm{ml}$; range 301-2292 $\mu \mathrm{URT} / \mathrm{ml}) \mathrm{RT}$ activity was detected in HEK293 cells exposed to encapsulated PK15 cells (Figure 1B).

In order to confirm if the RT activity was due to the presence of viral RNA during replication, qRT-PCR analysis was carried out on HEK293 cell supernatants. Analysis showed detectable PERV RNA in each replicate of HEK293 cells exposed to free PK15 cells at weeks 2, 4, 6 and 8 (Figure 2A, 2B, 2C and 2D). PERV RNA was also detected in cells exposed to encapsulated PK15 cells with PERV RNA in replicates B and C observed at weeks 2 and 4 (Figure 2A and 2B) and replicates $A, B$ and $C$ at weeks 6 and 8 (Figure 2C and 2D).

In order to determine if the detected PERV RNA and RT represented free or degraded PERV RNA, RT escaped from cells undergoing apoptosis or PERV virions released from cells and transmitted across the alginate barrier, capsid integrity testing was carried out. This assay confirms the presence of PERV RNA encapsulated in an intact virion. The capsid integrity testing indicated that intact virions were only detectable in HEK293 cell culture media in cells exposed to free PK15 cells at weeks 2, 46 and 8 (Table 2), and only in one of the experimental replicates of the HEK293 cells exposed to encapsulated PK15 cells (replicate C) at weeks 6 and 8 (Table 2). Similarly, western blot analysis of HEK293 culture media (Figure 
3) detected PERV gag in culture media from HEK293 free PK15 exposed cells and in only one replicate (C) of HEK293 encapsulated PK15 exposed cells at week 8.

In addition to testing for PERV RNA and RT in the cell supernatant, it was important to assess if any proviral DNA was detectable in the cells over time indicative of active infection and integration. The presence of proviral DNA was confirmed in ST cells at all time points as to be expected due to the presence of PERV in this cell line. Likewise, proviral DNA was detected in the cell lysates from HEK293 cells cultured with free PK15 cells. However, over the 8 week period no proviral DNA was detected in the cell lysates from HEK293 cells exposed to encapsulated islet or PK15 cells over all experimental time points (data not shown). 


\section{Discussion}

Previous work had demonstrated that this device was permeable to small molecules like insulin but constituted an efficient barrier to microbes or large cell fragments and impurities during its subcutaneous application ${ }^{4}$. The aim of this study was to assess the protective capacity of the alginate bio-barrier to prevent the release of PERV from encapsulated cells. No evidence of PERV infection, or no de novo PERV infection, was found in the HEK293 or ST cells co-cultured with encapsulated porcine islets.

Indeed, there was no increase in PERV RNA or RT in supernatants taken from ST cells cocultured with encapsulated high level PERV producing PK15 cells. It should be noted that ST cells have a background RT and RNA level which is deducted to evaluate whether an increase has occurred or not, i.e., active infection and replication.

Both HEK293 and pig cells cultured with free PK15 cells were positive for PERV RNA and RT, and the presence of PERV virions as detected by Western blot analysis.

However, PERV RNA, RT and virus was detected in 1 of the 3 experimental replicates of HEK293 cells co-cultured with encapsulated PK15 cells.

This data would suggest that alginate may represent an effective barrier to PERV escape and that encapsulated porcine islet cells could represent a low risk in relation to PERV. Previous studies have been unable to demonstrate PERV infection from islet cells in vitro to susceptible cell lines ${ }^{9,10}$ and in vivo studies which reported an absence of PERV in encapsulated porcine islet recipients ${ }^{2,5,7,11-16}$. This would suggest that islets are low risk for PERV release and infection and along with encapsulation, this could reduce the risk even more. Indeed, it has also been suggested that islets may not harbour many of the viral pathogens identified in the donor pig $^{17}$. However, we recognise that this study was conducted for a relatively short time period of 8 weeks and that a longer study would be valuable in examining this further. Although, it should be noted that PK15 cells used in this study are high PERV producers and it is likely a lower barrier of protection is required to protect as against PERV transmission from islet cells. 
Unfortunately a limitation of the study is that we did not confirm the viability of the cells post experiment to determine if cells were still viable after the 8 week period. We also do not know if the prepared device for macroencapsulation had been subject to any degradation or breach during the experiment. We do know that macroencapsulated islet cells survive for long periods in vivo ${ }^{4}$ and that the alginate matrix used in this study has been fully evaluated ${ }^{18}$. The islet cells used in these experiments were macro-encapsulated, which utilises alginate at a $3 \%$ concentration. In the case of islet micro-encapsulation, an alginate concentration of $1-1.5 \%$ is usually utilised. Whether this change in alginate concentration would impact the protection the device offers to PERV release remains unknown. However, the permeability of the device is thought to be related more to the gelling solution, rather than the alginate concentration ${ }^{19}$. In addition, the permeability of this device is known to be $150 \mathrm{KDa}$; previous studies have demonstrated that PERV transmission is significantly reduced by membranes with a nominal molecular weight cut-off of $\leq 400 \mathrm{KDa}^{20}$ or $35 \mathrm{~nm}^{21}$, however RNA and/or RT have been seen to not be restricted by this pore size. Nyberg et al have demonstrated that the RNA of PERV is small enough to cross the pores in membranes of $70 \mathrm{kDa}$ MWCO ${ }^{20,21}$. The diameter of PERV is approximately $100 \mathrm{~nm}^{22}$, therefore it is feasible that where we identify RNA and/or RT this is a valid positive detection based on pore size, but the alginate does appear to exclude PERV viral particles. Based on this, it could be proposed that in replicate C, where PERV virus was detected by Western blot, the device had become compromised in comparison to replicates $A$ and $B$ allowing the release of particles. Likewise, the detection of RT at each time point in the presence of PK15 cells may represent viability as the cells are still producing replicating virus. This also highlights the importance of quality control and good manufacturing procedures in the production of encapsulated islet devices. To date no in vivo transmission of PERV in patients receiving encapsulated islet xenografts has been reported. Based on this study and previous work, it may be that the use of encapsulation/membrane filters do indeed protect or reduce the risk of PERV. Further studies examining the permeabilty of alginate to other viruses, such as hepatitis $E$, could also prove valuable in understanding the risk of zoonosis posed by exogenous virus in the use of porcine derived encapsulated islets. 


\section{References}

1. Basta, G. et al. Long-Term Metabolic and Immunological Follow-Up of Nonimmunosuppressed Patients With Type 1 Diabetes Treated With Microencapsulated Islet Allografts: Four cases. Diabetes Care 34, 2406-2409 (2011).

2. Matsumoto, S. et al. Clinical Porcine Islet Xenotransplantation Under Comprehensive Regulation. Transplant. Proc. 46, 1992-1995 (2014).

3. Cooper, D. K. C. et al. Progress in Clinical Encapsulated Islet Xenotransplantation. Transplantation 100, 2301-2308 (2016).

4. Dufrane, D., Goebbels, R.-M. \& Gianello, P. Alginate macroencapsulation of pig islets allows correction of streptozotocin-induced diabetes in primates up to 6 months without immunosuppression. Transplantation 90, 1054-62 (2010).

5. Morozov, V. A. et al. No PERV transmission during a clinical trial of pig islet cell transplantation. Virus Res. 227, 34-40 (2017).

6. Mourad, N., Perota, A., Xhema, D., Galli, C. \& Gianello, P. Transgenic expression of glucagon-like peptide 1 (GLP-1) and activated muscarinic receptor (M3R) significantly improves pig islet secretory function. Cell Transplant. (2016).

doi:10.3727/096368916X693798

7. Paradis, K. et al. Search for cross-species transmission of porcine endogenous retrovirus in patients treated with living pig tissue. The XEN 111 Study Group. Science 285, 1236-41 (1999).

8. Pizzato, M. et al. A one-step SYBR Green I-based product-enhanced reverse transcriptase assay for the quantitation of retroviruses in cell culture supernatants. J. Virol. Methods 156, 1-7 (2009).

9. Irgang, M. et al. No evidence for PERV release by islet cells from German landrace pigs. Ann. Transplant. 13, 59-66 (2008).

10. Clémenceau, B., Jégou, D., Martignat, L. \& Saï, P. Long-term follow-up failed to detect 
in vitro transmission of full-length porcine endogenous retroviruses from specific pathogen-free pig islets to human cells. Diabetologia 44, 2044-55 (2001).

11. Tuch, B. E. et al. Safety and viability of microencapsulated human islets transplanted into diabetic humans. Diabetes Care 32, 1887-9 (2009).

12. Elliott, R. B. et al. No evidence of infection with porcine endogenous retrovirus in recipients of encapsulated porcine islet xenografts. Cell Transplant. 9, 895-901

13. Garkavenko, O. et al. Monitoring for Presence of Potentially Xenotic Viruses in Recipients of Pig Islet Xenotransplantation. J. Clin. Microbiol. 42, 5353-5356 (2004).

14. Valdés-González, R. A. et al. Xenotransplantation of porcine neonatal islets of Langerhans and Sertoli cells: a 4-year study. Eur. J. Endocrinol. 153, 419-27 (2005).

15. Elliott, R. B. et al. Live encapsulated porcine islets from a type 1 diabetic patient $9.5 \mathrm{yr}$ after xenotransplantation. Xenotransplantation 14, 157-61 (2007).

16. Wynyard, S., Nathu, D., Garkavenko, O., Denner, J. \& Elliott, R. Microbiological safety of the first clinical pig islet xenotransplantation trial in New Zealand. Xenotransplantation 21, 309-23 (2014).

17. Crossan, C., O’Hara, Z., Mourad, N., Gianello, P. \& Scobie, L. Examining the potential for porcine-derived islet cells to harbour viral pathogens. Xenotransplantation e12375 (2017). doi:10.1111/xen.12375

18. Vériter, S. et al. In Vivo Selection of Biocompatible Alginates for Islet Encapsulation and Subcutaneous Transplantation. Tissue Eng. Part A 16, 1503-1513 (2010).

19. Strand, B. L., Coron, A. E. \& Skjak-Braek, G. Current and Future Perspectives on Alginate Encapsulated Pancreatic Islet. Stem Cells Transl. Med. 6, 1053-1058 (2017).

20. Nyberg, S. L., Hibbs, J. R., Hardin, J. A., Germer, J. J. \& Persing, D. H. Transfer of porcine endogenous retrovirus across hollow fiber membranes: significance to a bioartificial liver. Transplantation 67, 1251-5 (1999).

21. Shi, X.-L. et al. Factors Influencing the Transfer of Porcine Endogenous Retroviruses across the Membrane in Bioartificial Livers. Int. J. Artif. Organs 35, 385-391 (2012). 
22. Armstrong, J. A., Porterfield, J. S. \& De Madrid, A. T. C-type virus particles in pig kidney cell lines. J. Gen. Virol. 10, 195-8 (1971). 
This work was supported by a European Commission FP7 funded project XENOISLET (project number 601827). 


\section{Figure Legends}

Figure 1: Mean values of reverse transcriptase analysis, performed by SG-PERT, of culture medium from $n=3$ replicates for weeks $2,4,6,8$ from a) ST co-culture experiments, where asterisks indicate statistical significance $(*=p<0.05, * * * * p=<0.0001)$, indicating significantly higher RT activity only in ST cell exposed to free PK15 cells. b) HEK293 co-culture experiments, showing high RT activity detected at weeks 4, 6 and 8 in the media of HEK293 cells exposed to free PK15 cells, low RT activity in the media of HEK293 cells exposed to encapsulated PK15 cells and no RT activity detected in the media of the other experimental cells.

Figure 2: PERV RNA copies per $\mathrm{ml}$ of culture medium, as determined by qRT-PCR analysis, for each experimental replicates (A-C) for weeks 2 (2a), 4 (2b), 6 (2c), 8(2d) from HEK293 coculture experiments showing detectable PERV RNA in media from all replicates exposed to free PK15 cells at weeks 2,4, 6 and 8 and 2 replicates from the cells exposed to encapsulated PK15 cells at weeks 2 and 4 and from all 3 replicates at weeks 6 and 8 .

Figure 3: PERV gag protein analysis, by western blot, of HEK293 culture media co-cultured with encapsulated islets, encapsulated PK15 cells, free PK15 cells and negative controls at weeks 2, 4, 6 and 8 showing detectable PERV gag protein in the culture media of all 3 replicates of HEK293cells exposed to free PK15 cells at weeks 4, 6, and 8 and one replicate of HEK293 cells exposed to encapsulated PK15 cells. 
Figures

Figure 1

a)

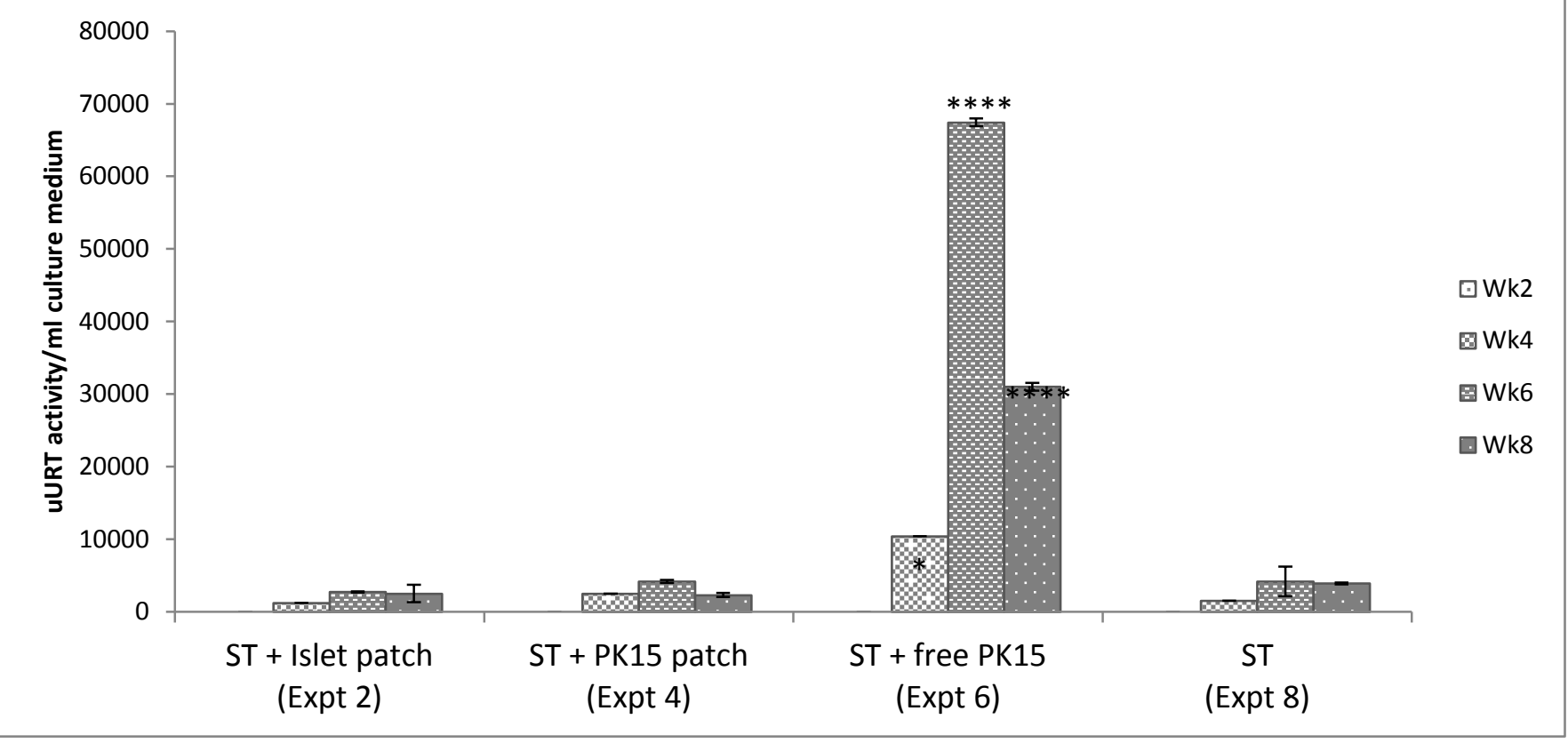

b)

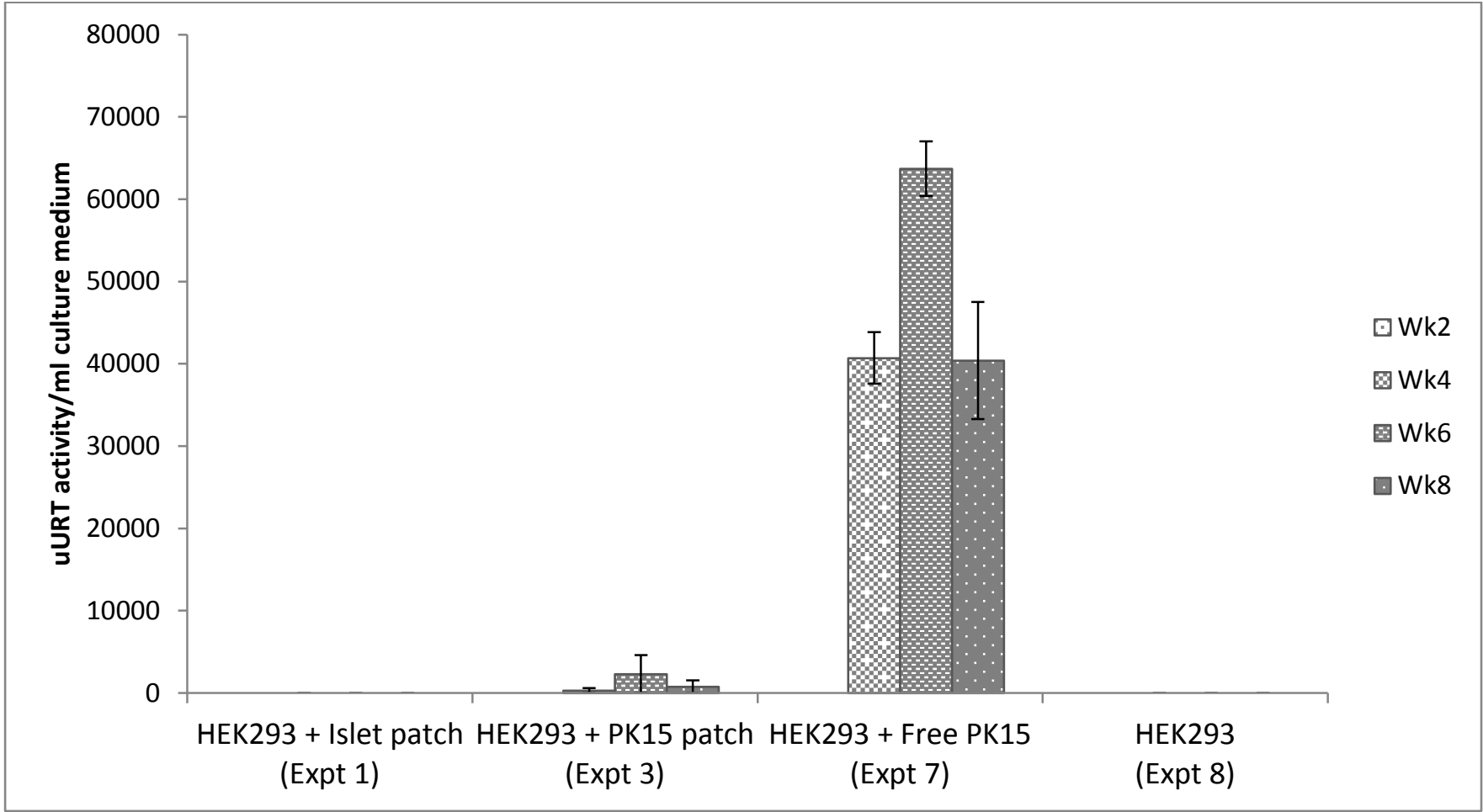


Figure 2

a)

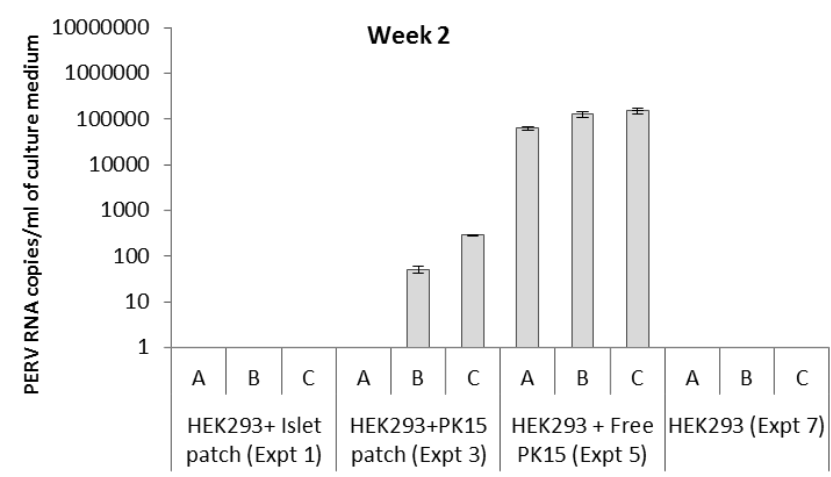

c)

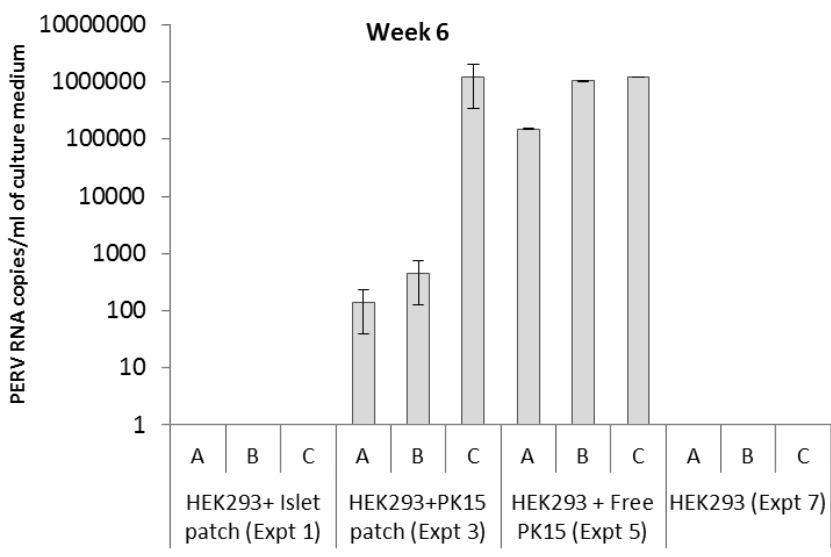

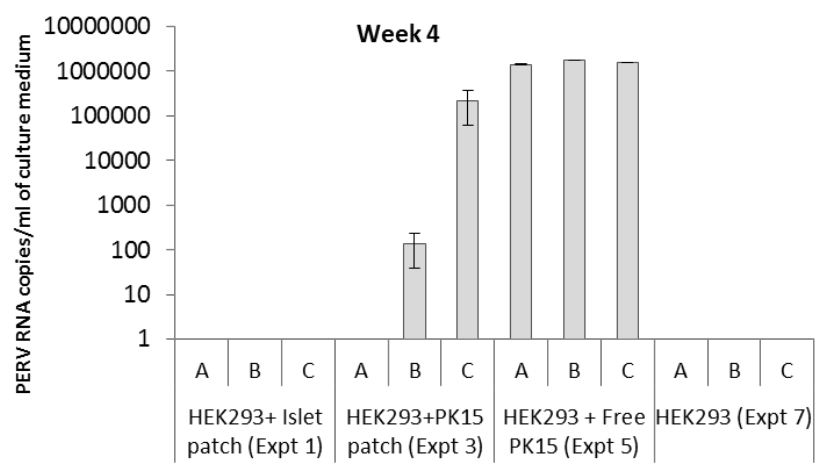

d)

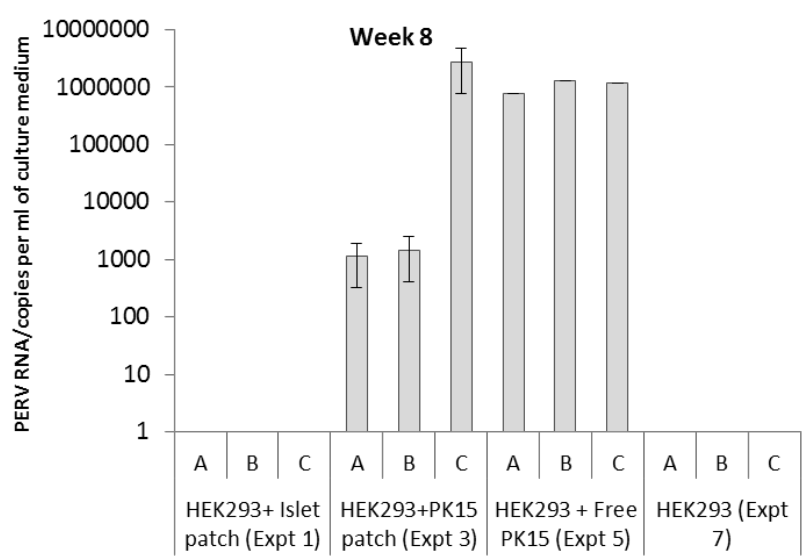


Figure 3:

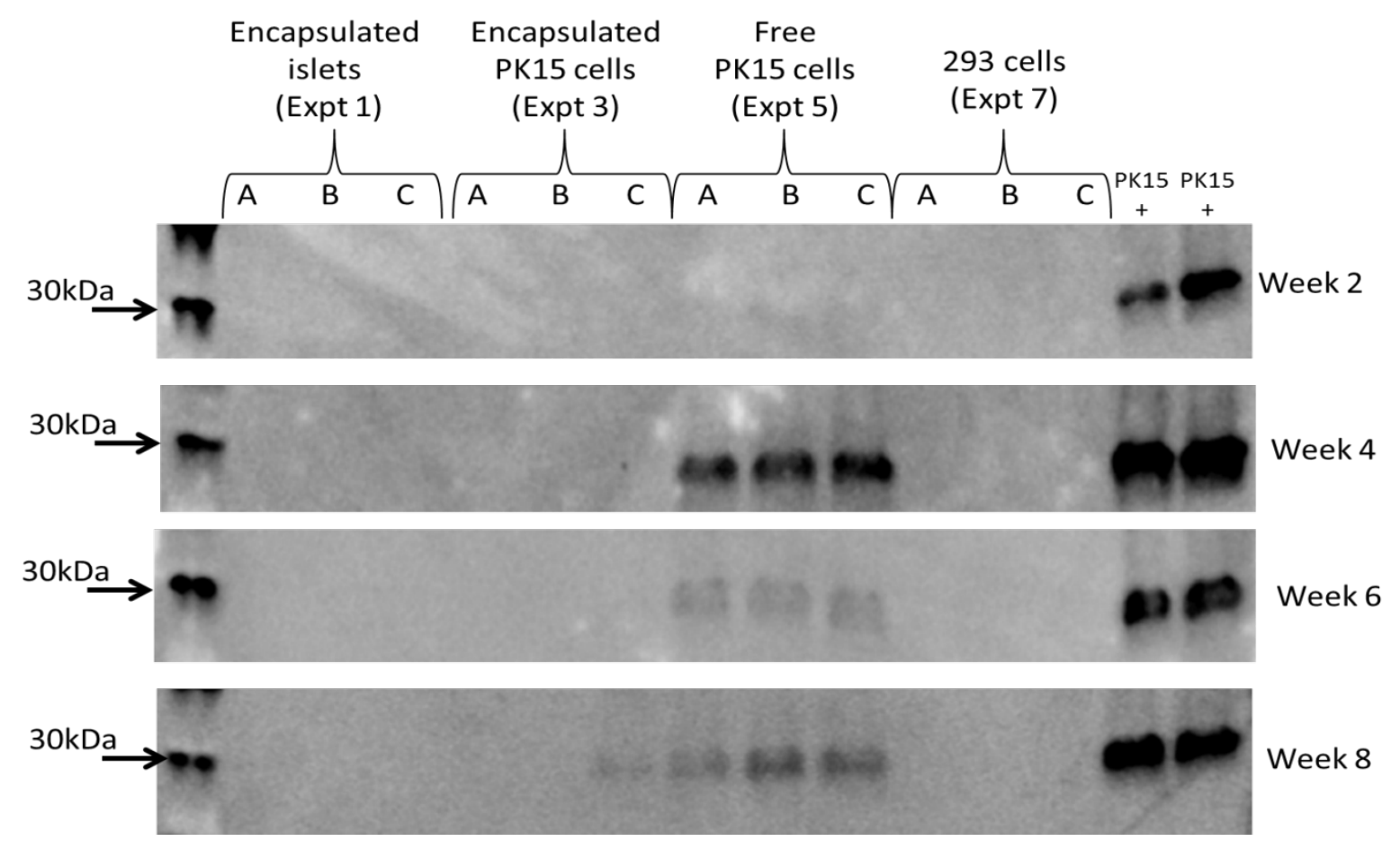

